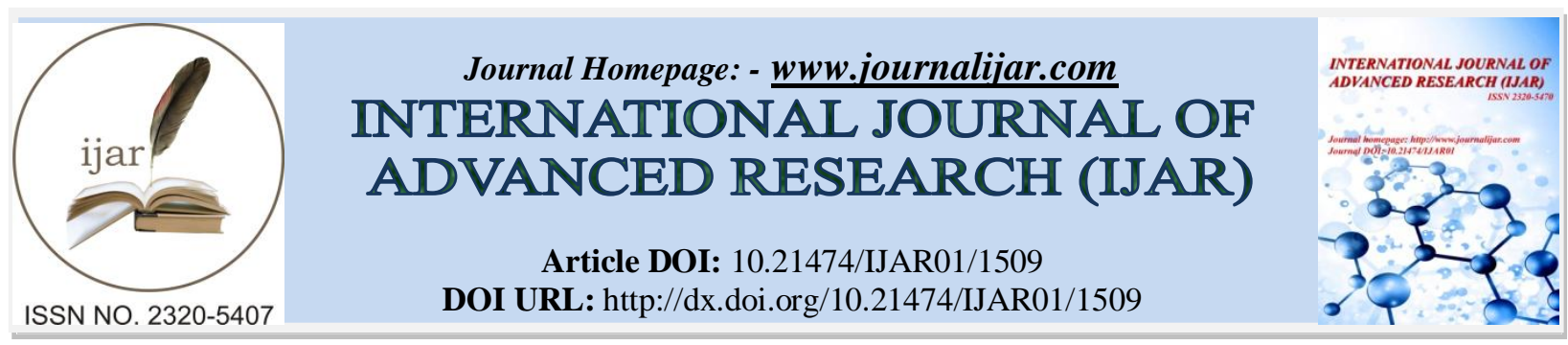

RESEARCH ARTICLE

\title{
BIODIVERSITY OF CHIRONOMIDAE (DIPTERA) FROM UDAIPUR REGION (INDIA)
}

\author{
Dr. Preeti Singh and Deepak Rawal*- \\ Department of Zoology, Mohanlal Sukhadia University, Udaipur, India. PIN 313001.
}

\section{Manuscript Info}

Manuscript History

Received: 19 July 2016

Final Accepted: 16 August 2016

Published: September 2016

Key words:-

Chironomidae, Udaipur, Einfeldia,

Polypedilum, Chironomus.

\section{Abstract}

Present study was conducted at four sampling sites viz.: Fatehsagar Lake, Pichola Lake, Udaisagar Lake and Ayad River at Udaipur region, India. Biodiversity analysis of Chironomids up to generic level showed that Chironomids are most diverse at Udaisagar Lake. Udaisagar provides dominant site for Chironomids. Complete dominance of Chironominae in all four sampling sites is related to their adaptability and survival in low oxygen environments due to presence of hemoglobin analog in their bodies. Genus Chironomus was found to be absent in Fatehsagar and Pichola Lake. This study also refutes the myth that every red colored larvae collected for study of polytene chromosome in this area is Chironomus.

Copy Right, IJAR, 2016,. All rights reserved.

\section{Introduction:-}

Chironomids, often called non-biting midges or blind mosquitoes, are abundant and widespread aquatic insects. These insects spend the greatest part of their life cycle in larval form, occupying a wide range of habitats. Chironomids are one of the most dominant, widespread and diverse aquatic invertebrate taxa in freshwater systems (Armitage et al 1995). Chironomids are distributed from the Arctic to the Antarctic and from the seas to permanent snowfields. Chironomids live in the glaciated areas of the highest mountains, including an elevation up to 5600 meters in the Himalaya (Kohshima 1984; Saether \& Willasse 1987) and are active at a temperature of $-16^{\circ} \mathrm{C}$. Larvae of Sergentia live at over 1000 meters depth in the abyss of Lake Baikal (Linevich 1963). The family Chironomidae is a cosmopolitan group of dipteran insects representatives of which occur in all zoogeographic regions of the world (Ashe et al 1987). The seven zoogeographical regions viz.: Antarctica, Australoasian, Afrotropical, Nearctic, Neotropical, Oriental and Palearctic includes ten subfamilies of Chironomidae viz. Aphroteniinae, Buchonomyiinae, Cheilenomyiinae, Chironominae, Diamesinae, Orthocladiinae, Podonominae, Prodiamesinae, Tanypodinae and Telmatogetoninae. Chironomids spend most of their lives as benthic larvae living and feeding on the sediment (Oliver 1971). Chironomids are closely related to mosquitoes (Culicidae) and biting midges (Ceratopogonidae). Unlike Culicidae and Ceratopogonidae, female Chironomids do not bite due to the absence of elongated mouthpart and they lack wing scales too. The larvae of most Chironomids hatch out from the eggs and usually lead bottom dwelling life forming tubes with the help of silk secreted from the salivary glands taking and taking of clay particles and organic matters from the substratum. Some forms are found to live inside muddy substratum. Chironomids are an important food source for large predatory invertebrates, fishes, and birds (Hudson et al 1990). Chironomids are important contributors of carbon and energy flow to higher trophic levels (Benson et al, 1980). Chironomids have an important role in aquatic food webs, representing a major link between producers, such as phytoplankton and benthic algae and secondary consumers (Tokeshi 1991).

Corresponding Author:- Deepak Rawal.

Address:- Department of Zoology, Mohanlal Sukhadia University, Udaipur, India. PIN 313001. 


\section{Materials and methods:-}

Larval Chironomids were collected from four geographic sampling sites in Udaipur viz. - Fatehsagar Lake, Pichola Lake, Udaisagar Lake and Ayad River. Random samplings were done on each of the four sampling sites. They were collected by sieving substrate with $0.5 \mathrm{~mm}$ sieve near the shore and evaluated for their density. Then collected larvae were carried to the laboratory in plastic bottles. Then larvae were examined under a compound microscope for identification up to genera using keys (Epler, 2001). Altitudes, Longitudes and Latitudes for each sampling site were recorded with the aid of Spice android one Smartphone GPS. Randomly collected 100 larvae in each sampling were used for diversity analysis. Shannon- Wiener diversity index $\left(\mathrm{H}=-\sum \mathrm{Pi}\right.$ In Pi), Simpson index (1-D), Dominance (D) and evenness (E) was applied for calculating diversity. Data analysis and statistics was done using Past software.

\section{Results and Discussion:-}

Present study was conducted at four sampling sites viz. Fatehsagar Lake, Pichola Lake, Udaisagar Lake and Ayad River. These sites represents Udaipur region well because of their geographic location all around Udaipur and covers both lentic (Lakes) and lotic (River) habitats (Table 1).

Table 1:- Geography of sampling sites.

\begin{tabular}{|l|l|l|l|l|}
\hline Location & Latitude (N) & Longitude (E) & $\begin{array}{l}\text { Altitude (m. a. s. } \\
\text { 1.) }\end{array}$ & Habitat \\
\hline Fatehsagar & 24.608225 & 73.677421 & 567 & Lentic \\
\hline Pichola & 24.563055 & 73.682431 & 569 & Lentic \\
\hline Udaisagar & 24.577515 & 73.825043 & 546 & Lentic \\
\hline Ayad & 24.582585 & 73.724183 & 558 & Lotic \\
\hline
\end{tabular}

Chironomid larvae were distinguished from other Dipteran larvae by following features.

1. Spiracles absent (apneustic)

2. Prolegs on first thoracic and terminal abdominal segments.

3. Terminal abdominal segment with paired procerci, each bearing a tuft of setae.

Subfamily Chironominae was distinguished from other subfamilies of Chironomidae with following larval characters.

1. Ligula absent.

2. Mentum present.

3. Two eye spots present.

4. Striated ventro-mental plate present.

5. Non-retractile antennae present.

Tribe Chironomini was distinguished with following larval characters.

1. Antenna has 5 segments.

2. Mentum has 12 lateral teeth.

Three genera identified in this study, possess following distinguished larval characters (Table 2)-

Table 2:- Distinguished larval characters of three identified genera.

\begin{tabular}{|l|l|l|l|}
\hline Characters & Einfeldia Kieffer & Polypedilum Kieffer & Chironomus Meigen \\
\hline color & Red & Red & Red \\
\hline Size & Medium sized & Smaller & Large sized \\
\hline Mentum & Simple median tooth & Dark, 4 median teeth & Trifid median tooth \\
\hline Mandibles & Light, 2 inner teeth & Dark, 3 inner teeth & Light, 3 inner teeth \\
\hline Ventral tubules & One pair, Short, uncoiled & Absent & Two pairs, long, coiled \\
\hline
\end{tabular}

Chironomidae family has been divided into 11 subfamilies (Chironominae, Orthocladiinae, Prodiamesinae, Diamesinae, Buchonomyiinae, Chilenomyiinae, Tanypodinae, Usumbaromyiinae, Podonominae, Aphroteniinae and Telmatogetoninae. Chaudhuri et al (2001) prepared a checklist of Chironomid midges of the Indian subcontinent. It includes 313 species under 60 genera under four subfamilies. Four subfamilies are Diamesinae, Tanypodinae, 
Orthocladiinae and Chironominae, there are no Chironomid species reported from Rajasthan. However, Chironomus circumdatus was identified later in Jaipur (Sharma \& Gupta 2014) which is $340 \mathrm{~km}$ far from Udaipur. Three genera reported in present study belong to single subfamily Chironominae.

Table 3:- Diversity status of Chironomids in four sampling sites.

\begin{tabular}{|l|l|l|l|l|}
\hline Taxa & Fatehsagar & Pichola & Udaisagar & Ayad \\
\hline Chironomus & Not found & Not found & $7.33 \%$ & $17.33 \%$ \\
\hline Polypedilum & $20.66 \%$ & $21.66 \%$ & $13.33 \%$ & Not found \\
\hline Einfeldia & $79.33 \%$ & $78.33 \%$ & $78.66 \%$ & $82.66 \%$ \\
\hline
\end{tabular}

Chironomus was found to be absent in Fatehsagar and Pichola Lake. This may be due to their non resilience. Polypedilum and Einfeldia were found to be in equal percentage in Fatehsagar and Pichola, this may be due to their common drainage system. Polypedilum was found to be absent in Ayad due to their lentic habitat preference and Udaisagar have all three subfamilies, may be due to isolated habitat getting drainage from both Ayad River and other sources in rainy season. However we have to keep in mind that Chironomids can disperse not only in larval forms but also in their adult forms through flying. So there is free interbreeding may present in all sampling sites because Fatehsagar and Pichola Lakes are adjacent and Ayad River connects both lakes to Udaisagar Lake. Complete dominance of Chironominae in all four sampling sites is related to their adaptability and survival in low oxygen environments due to presence of hemoglobin analog in their bodies.

Biodiversity analysis of Chironomids up to generic level showed that Chironomids are most diverse at Udaisagar Lake. This may be due to water quality remain constant in this water bodies and water is available all year. Udaisagar provides dominant site for Chironomids because only hardy Chironomid species can survive off rainy season. Water level of Udaisagar gradually falls in off rainy season. We know that Chironomids live near shore in benthic habitat and eat soft detritus. So only highly adaptable can survive and became dominant. The decrease in diversity in Ayad River is related to organic and industrial pollution. It might also note that River is completely dry sometimes in the year. This may be another reason for less diversity. This study also refutes the myth that every red colored larvae collected for study of polytene chromosome, in this area is Chironomus.

Table 4:- Diversity indices of Chironomid taxa in four sampling sites.

\begin{tabular}{|l|l|l|l|l|}
\hline & Fatehsagar & Pichola & Udaisagar & Ayad \\
\hline Taxa & 2 & 2 & 3 & 2 \\
\hline Dominance (D) & 0.6721 & 0.6606 & 0.6507 & 0.7134 \\
\hline Simpson (1-D) & 0.3279 & 0.3394 & 0.3493 & 0.2866 \\
\hline Shannon (H) & 0.5094 & 0.5226 & 0.6466 & 0.4611 \\
\hline Evenness (E) & 0.8322 & 0.8432 & 0.6363 & 0.7929 \\
\hline
\end{tabular}




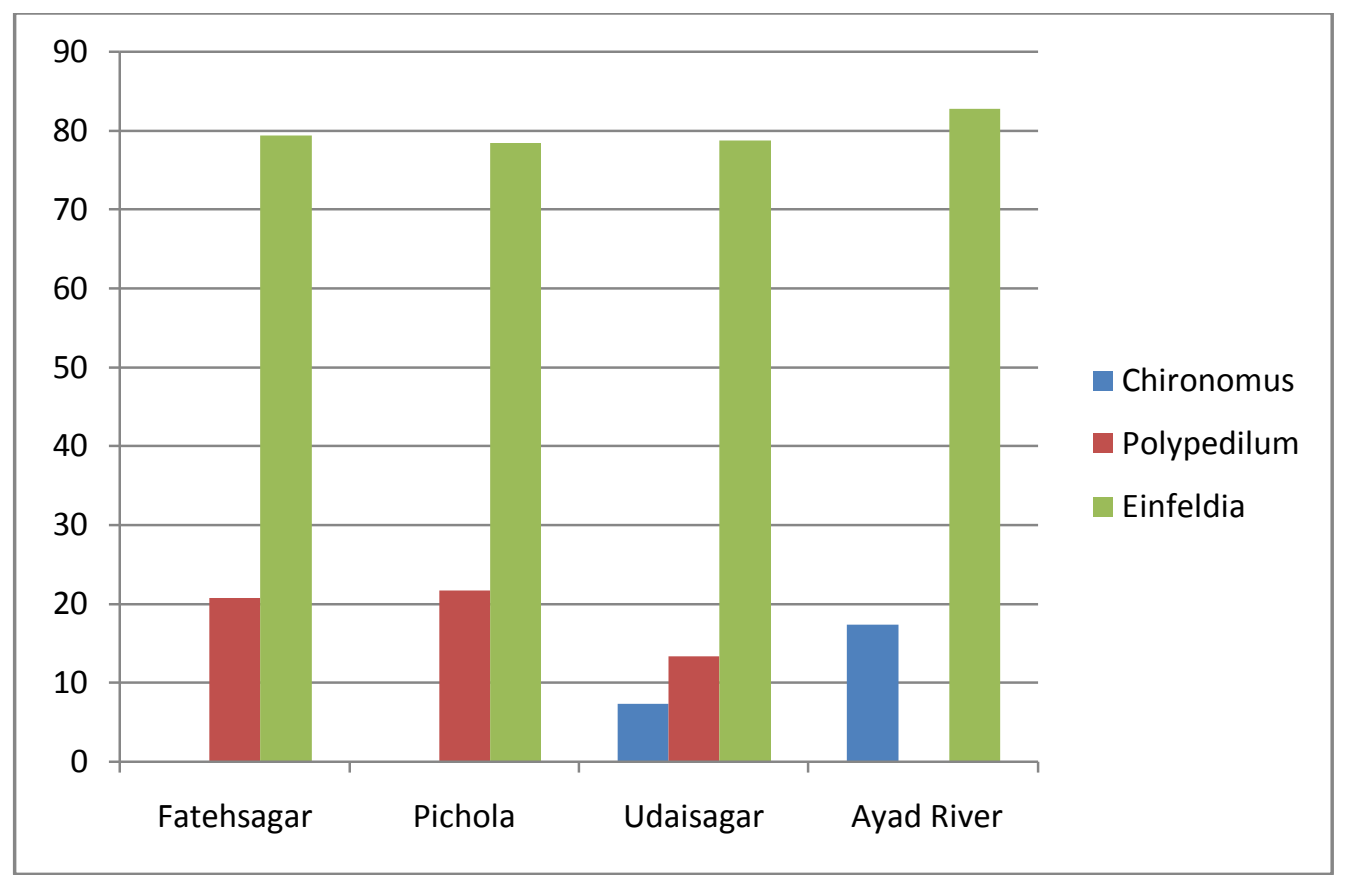

Graph 1:- Relative abundance of Chironomid genera in four sampling sites.

\section{References:-}

1. Armitage PD, Cranston PS and Pinder LCV. The Chironomidae: Biology and ecology of non-biting midges. $1^{\text {st }}$ ed. London, Chapman and Hall, 1995, 1-538.

2. Ashe P, Murray A and Reiss F. The zoogeographical distribution of Chironomidae (Insecta: Diptera). Annls. Limnol. 23 (1): 27-60, 1987.

3. Benson DJ, Fitzpatrick LC and Pearson WD. Production and energy flow in the benthic community of a Texas pond. Hydrobiologia, 74, 81-93, (11), 1980.

4. Chaudhuri PK, Hazra N and Alfred JRB. A checklist of Chironomid midges (Diptera: Chironomidae) of the Indian subcontinent. Oriental Insects 2001; 35: 335-372.

5. Epler JH. Identification manual for the larval Chironomidae (Diptera) of North and South Carolina, $1^{\text {st }}$ ed. North Carolina Department of Environment and Natural Resources Division of Waterr Quality, USA,2001, 1-526.

6. Hudson PL, Lenat DR, Caldwell BA and Smith D. Chironomidae of the Southeastern United States: A checklist of species and notes on biology, distribution, and habitat. Fish and Wildlife Research, 7 (4): 1-46, 1990.

7. Kohshima S. A novel cold-tolerant insect found in a Himalayan glacier. Nature, 310 (6), 225-227, 1984.

8. Linevich AA. K biologii komarov semeistva Tendipedidae 'Biologiya bespozvonochnykh Baikala'. Trudy Limnologicheskogo lnstituta, 1, 3-48 (1), 1963.

9. Oliver DR. Life history of the Chironomidae. Annual Review of Entomology, 16, 211-30, 1971.

10. Saether OA and Willasse E. Four new species of Diamesa Meigen, 1835 (Diptera: Chironomidae) from the glaciers of Nepal. Entomologica Scandinavica Supplement, 29, 189-203. [1][6], 1987.

11. Saether OA. Glossary of Chironomid morphology terminology (Diptera: Chironomidae). Entomologica Scandinavica Supplement 1980; 14: 1-51.

12. Sharma MR and Gupta V. Morphological identification of Chironomus larvae in Jaipur district (Rajasthan, India). International Journal of Scientific Research, 2014, 3(9): 413.

13. Tokeshi M. On the feeding habits of Thienemannimyia jestiva (Diptera: Chironomidae). Aquatic Insects, 13, 916, (12), 1991. 